\title{
A Forecasting Method Based on ARIMA Model for Best-Fitted Nutrition Water Supplement on Fruits
}

\author{
Saravanakumar Venkatesan, Sathishkumar V E, Changsun Shin, Yubin Kim, Yongyun Cho
}

\begin{abstract}
The main focus of this research is to promote a forecasting method in the greenhouse of cultivation for the nutrition water level of strawberry fruits. In the greenhouse of cultivation, this study selects strawberry fruits as the focus on research. With adequate nutrition water supply conditions, the autoregressive integrated moving average and seasonal autoregressive integrated moving average (ARIMA-SARIMA) were utilized to create forecasting for the nutrition water level of strawberry leaves in the fruit greenhouse of cultivation, thus forecasting strawberry's nutrition water rate through greenhouse environmental parameters. Next, the multi-scale feature vectors of greenhouse temperature and nutrition water parameters in the greenhouse have been extracted by using the data pre-processing method to eliminate the testing and training value of variables, thus improving the forecasting and generalization ability of the model. The extracted feature vectors have been used to train and optimize the SARIMA model, finally obtaining the forecasting model of nutrition water rate of strawberry fruits leaves in the greenhouse of cultivation, which has been compared in experiments with the autoregressive integrated moving average and seasonal autoregressive integrated moving average (ARIMA SARIMA) model. The results indicate that when training samples become a certain amount, the forecasting accuracy and regression fitting degree of ARIMA - SARIMA can be higher than that of the two traditional models. We forecasted that the strawberry greenhouse included 233 samples collected from a strawberry greenhouse in South Korea, and the 6 variables involved are greenhouse maximum temperature, greenhouse minimum temperature, greenhouse average temperature, quality of nutrient water, humanity, and $\mathrm{CO}_{2}$, which would influence the strawberry growth in production concentration directly or indirectly with the variation of nutrition water every day.
\end{abstract}

Keywords: Nutrition Water, Greenhouse Average Temperature, Humanity, Co2, ARIMA and SARIMA Model.

Revised Manuscript Received on December 30, 2019.

* Correspondence Author

Saravana kumar Venkatesan, Department of Information and Communication Engineering, Sunchon National University, Suncheon, South Korea. E-mail: skumarvsk1288@gmail.com

Sathish kumar V. E., Department of Information and Communication Engineering, Sunchon National University, Suncheon, South Korea.

Changsun Shin, Department of Information and Communication Engineering, Sunchon National University, Suncheon, South Korea. E-mail: csshin@sunchon.ac.kr

Yubin Kim, ELSYS Co., Ltd., Suncheon, Republic of Korea.

Yongyun Cho*, Department of Information and Communication Engineering, Sunchon National University, Suncheon, South Korea.

E-mail: yycho@scnu.ac.kr

(C) The Authors. Published by Blue Eyes Intelligence Engineering and Sciences Publication (BEIESP). This is an open access article under the CC BY-NC-ND license (http://creativecommons.org/licenses/by-nc-nd/4.0/)

\section{INTRODUCTION}

This study, greenhouse, functions as among the most important characteristics of nutrition water for commercial, greenhouse and agricultural supplies, but nutrition water resources have been using in many areas of the greenhouse. Resources are consumed at unsustainable levels and aroused various environmental and geological problems that seriously hamper the national economy's growth. To assist nutrition water for using in the effective management of greenhouse resources, it is necessary to develop a model of high precision for the forecast nutrition water level. Over the past year, nutrition water has the best way to keep up with continuous increases in greenhouse strawberry production, there are many approaches to nutrition water model that have beaning applied to forecast fluctuations in the nutrition water level within which; are the main climatological variables and describe the complex arrangement of aquifers. Nonetheless, in practice, these design methods have some limitations; for example, a model requires a large number of accurate data. In the event of insufficient data, accurate forecasting is more critical than understanding the surface water system's actual variable behaviour; thus, analytical models are suitable alternatives, since the models are available to produce accurate and reliable results without costing calibration time. Autoregressive integrated moving average (ARIMA) model is one of the empirical models with its specific characteristics that allow the system to be analyzed to generalize. This research also explores the relationship of greenhouse temperatures with other parameters of Co2 such as humidity, nutrition water heat. The aim of this paper is to use time series tools such as ARIMA and SARIMA model in time series forecasting. The statistical model generally works well in cases where lass is known as the underlying mechanism. The models will provide short-and medium-term food water forecasts. Using several statistical methods, the ARIMA and SARIMA output model will be tested. This research also examines the relationship of nutrition water with other parameters of growth of greenhouse strawberry such as humidity, Co2, temperature around other nutritional water, etc. The outcome form this paper can be utilised for decision-makers for their planning for future and how to maintain nutrition water in Greenhouse strawberry growth. 


\section{A Forecasting Method Based on ARIMA Model for Best-Fitted Nutrition Water Supplement on Fruits}

\section{MATERIALS AND METHOD}

\section{A. Strawberry growth details}

Strawberry growth is considered as the healthiest rising economy. Due to the high domestic demand of strawberry for every season, the production in greenhouse is increasing. Since the strawberry plant has an extremely shallow root sys tem with roots reaching just about 6-inches deep in clay loa $\mathrm{m}$ soils, and because flower blooms can be destroyed by spri ng frosts, irrigation is either strongly recommended or requir ed, depending on the production system. Water quality and site selection of a well-tended strawberry bed will produce a good crop of berries for 3-5 years before the plants begin to decline, at which point the bed should be replanted [1]. A bed of 100 plants will provide about 100 quarts of berries, enough to provide a family of four with plenty of fresh berries as well as the surplus for freezing. This study uses two types of the strawberry bed, to find which bed produces the best predicting of strawberry growth and best prediction of strawberry growth and the performance with the help of linear regression and correlation method. Finally, in result and discussion, we will show the best prediction of strawberry growth team annual precipitation is $55 \mathrm{~mm}$ (2015-2016), occurring mainly during autumn and winter.

I measure readings of water quantity of strawberry plant with a factor and temperature correction. We take this data on strawberry growth during the autumn and winter season, because it depends on temperature, it is more admitted to the level of nutrition water [2]. The activity of the water curtain system is close to changes in the minimum daily night-time temperature, and farmers seldom use the system when the forecast minimum night-time temperature is approximately 0 ${ }^{\circ} \mathrm{C}$. If outdoor air temperature reaches above $0^{\circ} \mathrm{C}$ at night, the temperature of the indoor air remains equal to or above $5^{\circ}$ $\mathrm{C}$ (the optimal temperature for strawberry cultivation) for the heat accumulated during the day and the insulating effects of the plastic cover.

\section{B. Strawberry Data Properties Determination}

In this study, we have used the greenhouse strawberry data in the year September 2015 to May 2016.

Table- I: Data variables and description

\begin{tabular}{|c|c|c|}
\hline Parameters/Features & Abbreviation & Measurement \\
\hline Date & Date & - \\
\hline Water Consumed & Water & Milli Litres \\
\hline $\begin{array}{c}\text { Greenhouse } \\
\text { Maximum } \\
\text { Temperature }\end{array}$ & GHMaxTemp & ${ }^{\circ} \mathrm{C}$ \\
\hline $\begin{array}{c}\text { Greenhouse } \\
\text { Minimum } \\
\text { Temperature }\end{array}$ & GHMinTemp & ${ }^{\circ} \mathrm{C}$ \\
\hline $\begin{array}{c}\text { Greenhouse Average } \\
\text { Temperature }\end{array}$ & GHAveTemp & ${ }^{\circ} \mathrm{C}$ \\
\hline $\begin{array}{c}\text { Greenhouse } \\
\text { Temperature Gap }\end{array}$ & GHTempGap & ${ }^{\circ} \mathrm{C}$ \\
\hline $\begin{array}{c}\text { Greenhouse } \\
\text { Maximum Humidity }\end{array}$ & GHMaxHum & $\%$ \\
\hline $\begin{array}{c}\text { Greenhouse } \\
\text { Minimum Humidity }\end{array}$ & GHMinHum & $\%$ \\
\hline $\begin{array}{c}\text { Greenhouse Average } \\
\text { Humidity }\end{array}$ & GHAveHum & ${ }^{\circ}$ \\
\hline
\end{tabular}

\begin{tabular}{|c|c|c|}
\hline $\begin{array}{c}\text { Greenhouse humidity } \\
\text { gap }\end{array}$ & GHHumGap & $\%$ \\
\hline $\begin{array}{c}\text { Greenhouse } \\
\text { Maximum CO2 Value }\end{array}$ & GHMaxCO2 & $\mathrm{ppm}$ \\
\hline $\begin{array}{c}\text { Greenhouse } \\
\text { Minimum CO2 Value }\end{array}$ & GHMinCO2 & $\mathrm{ppm}$ \\
\hline $\begin{array}{c}\text { Greenhouse Average } \\
\text { CO2 Value }\end{array}$ & GHAveCO2 & $\mathrm{ppm}$ \\
\hline $\begin{array}{c}\text { Greenhouse CO2 } \\
\text { Value Gap }\end{array}$ & GHCO2Gap & $\mathrm{ppm}$ \\
\hline
\end{tabular}

These strawberry data are based on nutrition water quantity, humidity, co2, greenhouse average temperature etc. Data were collected from a local strawberry park in Korea. 233 samples collected from greenhouse strawberry were collected by locally experienced strawberry growth, where all the sample were either healthy or unhealthy. The samples were taken to the analysing for a relationship in strawberry acquisition after collecting the nutrition water quantity and temperature Table 1 shows the data variables.

- Strawberry growth system: greenhouse maximum temperature and greenhouse minimum temperature greenhouse average temperature, quality of irrigation water, humanity, Co2 enrichment in greenhouse.

- This plan focused on the prediction of strawberry growth level and time (using nine month 24hour data). the shorter taught how to classify strawberry plant by size, variety and stage of strawberry growth using a ARIMA and SARIMA
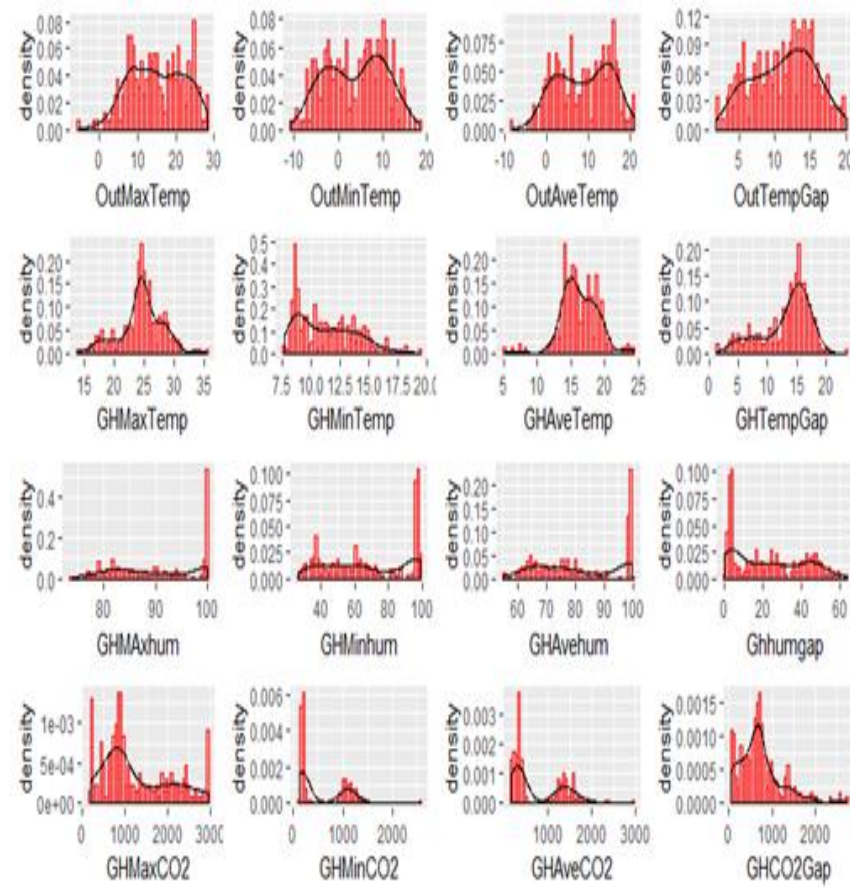

Fig.1. Real data variables density value

The data collected were rearranged and modified to remove the probable size for the first time. The strawberry data in greenhouse were used to determine horizontal water consumed over a span of 9 months. Figure 1 provides an overview of the function of density. 


\section{ARIMA Model}

Forecasting of the time series is a multidisciplinary scientific material used to solve issue of forecast [3]. It is easy and flexible to implement because it requires only historical observations of the necessary variables. Box and Jenkin presented ARIMA for the first time in 1976. The general equation of successive differences at the dth difference of $\mathrm{X} \mathrm{t}$ is as follows: figure 1 show the flowchart of time series model

$$
\Delta^{\mathrm{d}} X_{\mathrm{t}}=(1 \vdash \mathrm{B})^{\mathrm{d}} X_{\mathrm{t}}
$$

$\mathrm{d}$ is the difference order and is normally 1 or 2 , and $\mathrm{B}$ is the backshift operator. The successive difference at one-time lag equals to,

$$
\Delta^{\mathrm{d}} \mathrm{X}_{\mathrm{t}}=(1-\mathrm{B}) \mathrm{X}_{\mathrm{t}}-X_{\mathrm{t}}-1
$$

The general ARIMA (p, d, q) is briefly expressed as follows

$$
\phi_{\mathrm{P}}(\mathrm{B}) W_{\mathrm{t}}=\theta(\mathrm{B}) \mathrm{e}_{\mathrm{t}}
$$

where $\Phi \mathrm{p}(\mathrm{B})$ is an auto-regressive operator of order $\mathrm{p}, \theta \mathrm{q}(\mathrm{B})$ is a moving average operator of order $\mathrm{q}$,

and $\mathrm{Wt}=\Delta \mathrm{dXt}$.

\section{SARIMA Model}

The model of ARIMA is non-seasonal. This model has been generalized by Box and Jenkins to deal with seasonality. Their model is known as the prototype of the seasonal ARIMA (SARIMA) [4]. In this method, to exclude non-stationarity from the sequence, the seasonal distinction of correct order is used. A seasonal variation in the first order is the difference between an observation and the corresponding observation from the previous year and is determined from $\mathrm{Zt}=$ Yt-Yt-s with $\mathrm{s}=9$ for monthly time series and $s=4$ for quarterly time series. This model is commonly referred to as the SARIMA model (p, q, I (P, D, Q) SARIMA $(p, q, i) \times(P, D, Q)$ model in terms of lag polynomials is given below: figure 1 show the flowchart time series model.

$$
\begin{aligned}
& \phi_{p}\left(L^{s}\right) \varphi_{p}(L)(1-L)^{d}\left(1-L^{s}\right)^{D} y_{t}=\phi_{Q}\left(L^{s}\right) \theta_{q}(L) \varepsilon_{t} \\
& \text { i.e. } \phi_{p}\left(L^{s}\right) \varphi_{p}(L) z_{t=} \phi_{Q}\left(L^{s}\right) \theta_{q}(L) \varepsilon_{t}
\end{aligned}
$$

\section{E. Forecast Performance Criteria}

It is important to estimate the structure of the time series and evaluate the quality of the best-suited version before forecasting. In the research, there are many descriptive statistics available to assess some time series or econometric model's forecast errors [5]. The following contemporary template selection criteria, such as mean absolute error (MAE), root mean square error (RMSE), mean absolute percent error (MAPE), and mean percentage error (MPE), are used to identify the best model for production in strawberry. The MAE is a quantity used in statistics to calculate how close estimates or projections are to the possible outcomes. gives the mean absolute error.

$$
\text { MAE }=\frac{1}{n} \sum_{i=1}^{n}\left|f_{i}-y_{i}\right|
$$

The most commonly used variable is the RMSE. The main $r$ eason for this is its simplicity and use in other datasets. It ha $\mathrm{s}$ been described as

$$
R M S E=\sqrt{\frac{1}{\mathrm{n}}} \sum_{\mathrm{i}=1}^{\mathrm{n}}\left(y_{t}-\hat{y}\right)^{2}
$$

The percentage size of the error is measured by the MAPE. The sum of the unsigned percentage error is determined

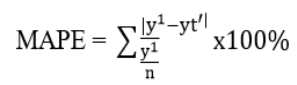

MPE is the percentage of error that occurred on average forecasting. MAPE, except that it indicates the error path. Conversely, signed errors impact and cancel each other. $M P E=\frac{1}{\mathrm{n}} \sum_{\mathrm{t}=1}^{\mathrm{n}}\left(\frac{\mathrm{e}_{\mathrm{t}}}{\mathrm{y}_{\mathrm{t}}}\right) \times 100$

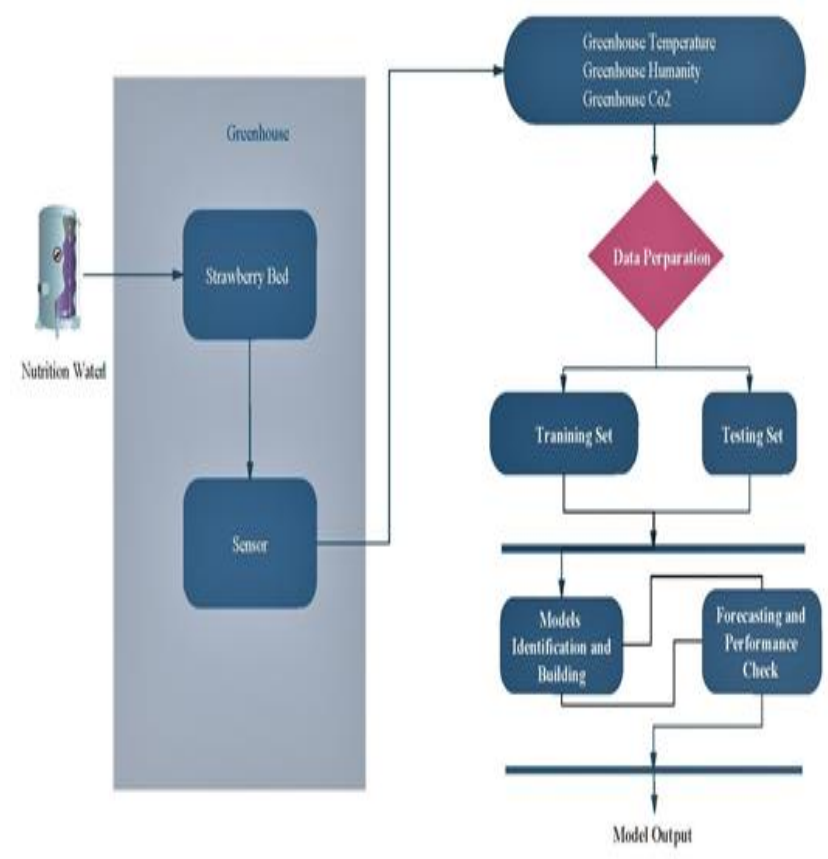

Fig. 2 Flowchart of the proposed procedure

\section{RESULT AND DISCUSSION}

For the development and testing of an ARIMA system, stationary time series data are prerequisites. The data collected were analyzed and the first distinction was applied to the stationarization of data. A Phillips-Perron test was performed using a mat lab code (pptest) to determine the first stationary difference in the results. This experiment will determine the null hypothesis of a unit root in a univariate time. [6] $\mathrm{Yt}=\mathrm{c}+\delta \mathrm{t}+\mathrm{a} \mathrm{Yt}-1+\mathrm{e}(\mathrm{t})$. The assumption of zero limits to equal 1 . The test models, suitable for series with different production characteristics, restrict the coefficients of drift and deterministic trend (i.e., c and d, respectively) to 0 . The experiments use updated statistics from Dickey-Fuller to compensate for serial comparisons in the (t) innovation phase.

Published By: 
The $\mathrm{h}=1$ Phillips - Perron test result shows that the first difference will adequately stationarize the data consumed by strawberry's monthly heat. Also, Figure 3 displays stationary time series data for 9month 24hour data greenhouse strawberry nutrition water consumed after the first difference was applied. The fluctuation clearly is around zero; therefore, they can be considered stationary. This result shows that the first difference is adequate and further processing of data is unnecessary.

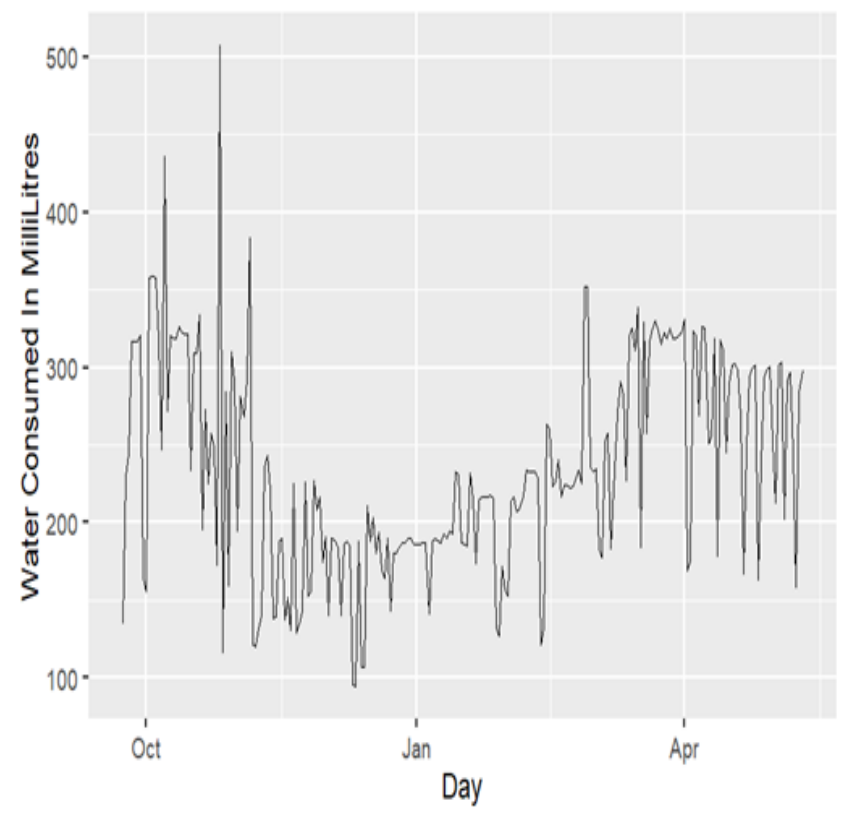

Fig.3. The nutrient water consumed by strawberry plants each day from September 2018 to May2019

The second difference is sufficient to stabilize the variance and make the data stationary, i.e. the order of difference is two, which is integrated of order two. The alternative positive and negative auto-correlation function (ACF) (Figure 4 (left side)) and the exponentially decreasing partial auto-correlation function (PACF) (Figure 4 (right side)) indicate that strawberry production development follows an autoregressive moving average process [7]. The PACF with a significant spike at lag 1 and ACF with a significant spike at lag 1 suggest that autoregressive first order and moving first order average were successful for Strawberry greenhouse output.
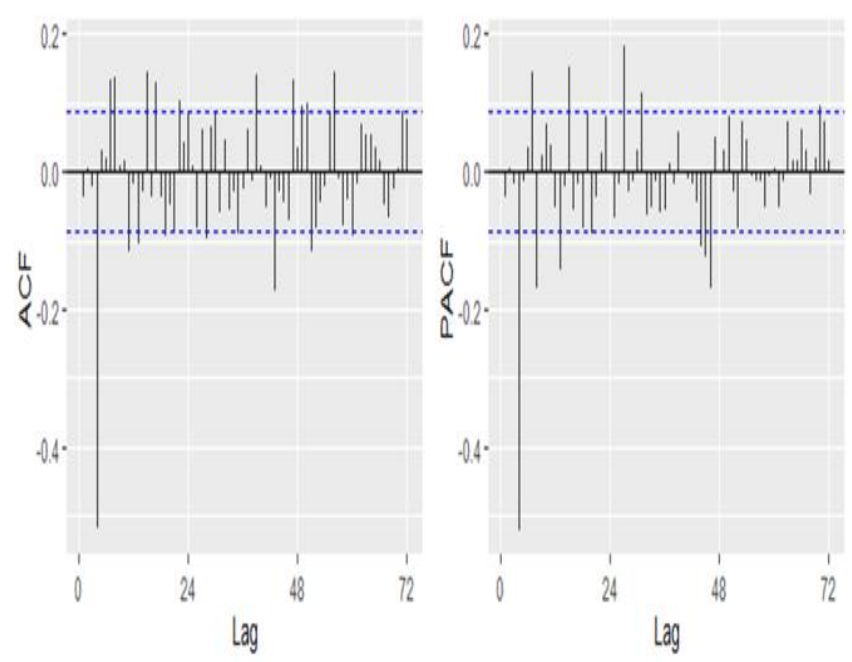

Fig.4. ACF and PACF plot nutrition water consumed

Figure 4 shows that for the consumed nutrition water (a) significant autocorrelations are resent at 12-fold lags, suggesting a seasonal action every 9 months. Nevertheless, in shorter lags, there are potentially significant auto-correlations. PACF declines after the fourth delay, so there is ACF declines then the second lag and, accordingly, the proposed SARIMA model is ARIMA $(0,1,3),(0,1,1)$ with a seasonal auto-regression (AR) of 12 and a moving average (MA) of 12. All possible combinations were tried with the smallest RMSE to determine the best model. Then the second lag of ACF with a low lag decline for PACF, the model showed reasonable results (statistically significant results) [8]. Therefore, ARIMA $(4,0,2),(2,0,0)$ was supposed to be the final version. Once, attempts were made to determine the splendid model and improve the model system through all possible combinations

Using the preliminary method, it is clear that SARIMA $(0,1,3)$ is the best-selected model for AIC $=5732.3$, AICc $=$ 5732.42 and BIC $=5753.39$ to forecast growth in Greenhouse Strawberry. Shown in Table 2

Table- II: Summary statistics of the SARIMA $(0,1,3)$ model

\begin{tabular}{|c|c|c|c|c|}
\hline \multirow{2}{*}{ Parameter } & \multicolumn{4}{|c|}{ Model Performance } \\
\cline { 2 - 5 } & Estimates & Std.Error & Z-Value & P-Value \\
\hline AR(1) & -0.137 & 0.0494 & -2.7714 & $0.0055^{* *}$ \\
\hline MA(1) & -0.838 & 0.0248 & -3.7901 & $2.20 \mathrm{E}-01$ \\
\hline SMA(1) & -0.003 & 0.0452 & -0.0755 & 0.9398 \\
\hline
\end{tabular}

Table 3 summarizes the ARIMA $(4,0,3)$ Is the best-selected development forecast model in greenhouse strawberry with $\mathrm{AIC}=5949.69, \mathrm{AICc}=5950.39$ and $\mathrm{BIC}=5992.64$. The estimates of the parameters of the fitted ARIMA $(0,1,3)$. 
Table- III: Summary statistics of the ARIMA $(4,0,2)$ model

\begin{tabular}{|l|l|r|r|c|}
\hline \multirow{2}{*}{ Parameter } & \multicolumn{4}{|c|}{ Model Performance } \\
\cline { 2 - 5 } & Estimates & Std.Error & Z-Value & P-Value \\
\hline AR(1) & 0.06 & 0.466 & 1.306 & 0.1914 \\
\hline MA(1) & -0.049 & 0.047 & -1.028 & 0.3038 \\
\hline MA(2) & 0.562 & 0.02 & -7.182 & $2.2 \mathrm{e}-16^{* *}$ \\
\hline
\end{tabular}

The standardized residual among them the forecast and scientific value for weekly nutrition water consumed were calculated for testing the product method. Figure 5 exposes that most of the standardized residuals for weekly nutrition water forecasts are between 1 ; thus, the standardized residuals the value of the proposed ARIMA system can be assumed to be automatically distributed [9]. The standardized residuals good and bad values often show model quality and imply that the expected values are sometimes higher or lower than the original values. Although some residuals fall further than the 2 limits, they reflect a limited number of readings and still remain within the $95 \%$ confidence interval that has been accepted. Ljung-Box test is a goodness-of-fit test, and it measures the skewness and kurtosis of the test data fit those of a confidence interval. This test can provide a null hypothesis decision. Whether the input data originates from a confidence interval with an unknown mean and variance [10]. The null hypothesis for the weekly greenhouse temperature is tested using the Ljung-Box test and the results of this study are in line with the scientific method at $\mathrm{P}=$ 1,887 , which refers to the normal distribution and nutrition water of the standardized residual.
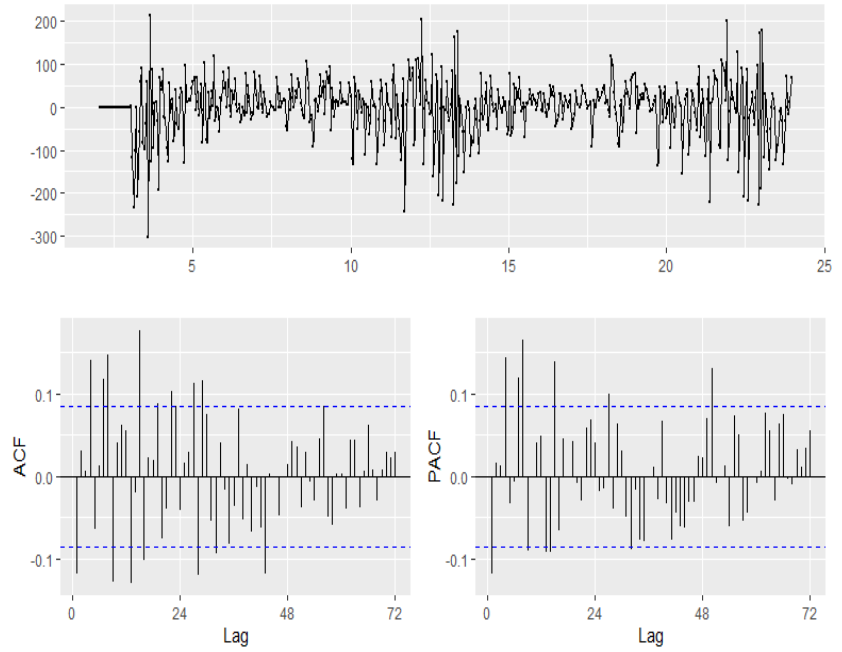

Fig.5. ACF and PACF plot of residuals of the fitted model water consumed data
The residual ACF and PACF were examined to assess the expected data's white noise. Figure 5 displays the ACF and PACF of the monthly nutrition water consumed models for 72 lags of residuals. The 72 lags presented are sufficient to model goodness Ljung-Box because most of the spikes with a propensity to decline are within the trust limits. The lags for both monthly nutrition water consumptions are within the essential value indicated by blue lines, and the residuals can be regarded as uncorrelated, suggesting the accurate model's goodness. The average number of residuals from ACF and PACF are beyond the critical limit, but these are relatively few and still within the $95 \%$ confidence interval accepted [11].

Long-term forecasting for lead times of 9 months was performed using the best models with real data of average for weekly and nutrition water consumed. Figure 6 presents the expected for weekly nutrition water consumed for the next 24 hours. The expected average for weekly nutrition water consumed value was within the range of 150-450. The common fluctuation trend was maintained, which can be explained by variations in nutrition water consumed due to change in greenhouse temperature conditions throughout the month. The common trend of monthly nutrition water consumption extended with time, as shown in Figure 6.it may be due to extended average temperature levels of the greenhouse as a result of nutrition water change and strawberry depletion [12]. The monthly nutrition water consumption is expected to reach 450. Figure 6 shows the expected average amount of nutrition water consumption for a month in advance. The fluctuation is existing for real average nutrition water consumed, and this fluctuation is kept with the forecasted values. The fluctuations for a forecasted average amount of the nutrition water consumption seemed to be larger in comparison with real inputs or forecasted monthly greenhouse strawberry [13].

The most useful "forecasts accuracy value" of the ARIMA and SARIMA model are shown in table 4. 

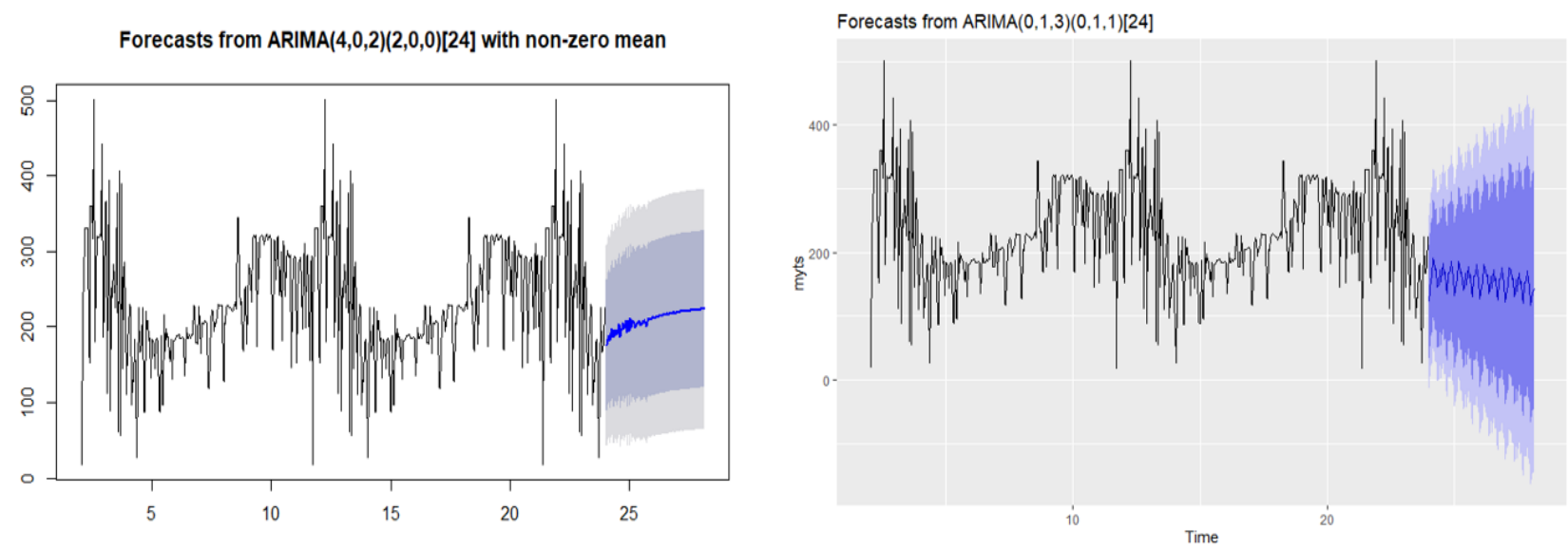

Fig. 6. ARIMA and SARIMA forecasts water data consumed by strawberry

Table- IV: The forecasting accuracy values of the ARIMA $(4,0,2)$ and SARIMA $(0,1,3)$ model

\begin{tabular}{|c|c|c|c|c|c|c|c|c|}
\hline \multirow{2}{*}{ Model } & \multicolumn{4}{|c|}{ Training } & \multicolumn{4}{c|}{ Testing } \\
\cline { 2 - 9 } & RMSE & MAE & MPE & MAPE & RMSE & MAE & MPE & MAPE \\
\hline ARIMA & 67.01 & 47.1 & -15.66 & 32.84 & 68.77 & 47.85 & -22.36 & 37.89 \\
\hline SARIMA & 59.21 & 48.17 & -19.66 & 35.71 & 61.21 & 48.9 & -25.36 & 39.54 \\
\hline
\end{tabular}

Finally, through the comparison test of the ARIMA and SARIMA model, the accuracy of the selected models for nutrition water in greenhouse strawberry and for precipitation is shown in Table 4.

We selected the most appropriate model from the models listed in Tables 2 and 3, which has the lowest forecast error when comparing predicted data using an appropriate test set. Also carried out was the Ljung-Box analysis and the p-values obtained are shown in tables 2 and 3. It follows from the above analysis that the statistical model that is the most suitable model for the considered data sets depends on the temperature zones from which they originate in the greenhouse. However, the results obtained show that applying SARIMA, ARIMA models to a nutrition water in greenhouse strawberry and a time series of precipitation provides valuable insights into the data structures studied and their components, which is a good basis for a satisfactory prediction. Table 4 and Figure 6 include examples of the predictions generating the smallest RMSE and passing the Ljung-Box test.

\section{CONCLUSION}

This research engaged in the development and comparison of two-time series models to predict the daily consumption of nutrient water of strawberry plants with the environmental data as like temperature, humidity and $\mathrm{CO}_{2}$ in a greenhouse. Each model, ARIMA and SARIMA, was trained with the nutrient water consumption data and the environmental data, which were regularly gathered from the greenhouse. As the result from the analysis test, the performance of SARIMA is best. This research uses only 9 months' data. since the data sets in this research is small, the future work will be concentrated on verifying this result and enhancing the prediction performance through proof test with data on nutrient water consumption gathered for more long time. Future work is to include more weather data and information from remote sensing [14] and to develop intelligent system to develop smart farming technology [15].

\section{ACKNOWLEDGMENT}

This work was supported by Korea Institute of Energy Technology Evaluation and Planning (KETEP) grant funded by the Korea government(MOTIE) (20194210100230, Development and substantiation of renewable energy fusion system for crops)

This work was carried out with the support of "Cooperative Research Program for Agriculture Science \&Technology Development (Project No. PJ01188605)" Rural Development Administration, Republic of Korea and, this research was supported by IPET (Korea Institute of Planning and Evaluation for Technology in Food, Agriculture, Forestry and Fisheries) through Advanced Production Technology Development Program, funded by MAFRA (Ministry of Agriculture, Food and Rural Affairs) (No. 315001-5)

\section{REFERENCES}

1. Sharp, Russell G. "A review of the applications of chitin and its derivatives in agriculture to modify plant-microbial interactions and improve crop yields." Agronomy 3.4: 757-793, 2013.

2. Yang, Yang, et al. "Short-term forecasting of daily reference evapotranspiration using the Penman-Monteith model and public weather forecasts." Agricultural water management 177: 329-339. 2016

3. Padhan, Purna Chandra. "Application of ARIMA model for forecasting agricultural productivity in India." Journal of Agriculture and Social Sciences 8.2, 2012.

4. Adanacioglu, Hakan, and Murat Yercan. "An analysis of tomato prices at wholesale level in Turkey: an application of SARIMA model." Custos e@ gronegócio on line 8.4: 52-75, 2012

5. Hasni, Abdelhafid, et al. "Applying time series analysis model to temperature data in greenhouses." Sensors \& Transducers 126.3: 119, 2017.

6. Alencar, David B., et al. "Hybrid approach combining SARIMA and neural networks for multi-step ahead wind speed forecasting in Brazil." IEEE Access 6 (2018): 55986-55994 
7. Abdul-Aziz, A. R., et al. "Modeling and forecasting rainfall pattern in Ghana as a seasonal ARIMA process: The case of Ashanti region." International Journal of Humanities and Social Science 3.3 (2013): 224-233.

8. Alsharif, Mohammed H., Mohammad K. Younes, and Jeong Kim. "Time series arima model for prediction of daily and monthly average global solar radiation: The case study of seoul, south korea." Symmetry 11.2 (2019): 240.

9. Mutwiri, Robert Mathenge. "Forecasting of Tomatoes Wholesale Prices of Nairobi in Kenya: Time Series Analysis Using Sarima Model." International Journal of Statistical Distributions and Applications 5.3 (2019): 46.

10. Curtis, Kynda R., et al. "Market and pricing potential for extended season fresh produce sales: An Intermountain West example." Journal of Food Distribution Research 45.856-2016-58146: 46-65, 2014.

11. Huang, Jeff, and Ken Nagasaka. "The trends of greenhouse gas emission for Japanese electric utility post Kyoto protocol." IJEAT 1 (2012): 2249-8958

12. Kolapkar, M. M., S. B. Sayyad, and V. J. Kakade. "Design of energy efficient smart wireless embedded system for study of greenhouse related parameters using multi-nodal sensing approach." International Journal of Computer Application, (0975-8887) GOTETC-IP 13 (2014): 8-12.

13. Rubina, M., and M. Vijaya Kumar. "Monitoring and Control of Greenhouse Gases Using Wireless Sensor Network." i-Manager's Journal on Embedded Systems 3.3 (2014): 9.

14. Sathishkumar V E, Usha Moorthy, Jangwoo Park, Changsun Shin, Yongyun Cho, "Internet Role in Remote Sensing and Geo Informatics System", International Journal of Innovative Technology and Exploring Engineering, Volume-9, Issue-2, Dec 2019.

15. Sathishkumar V E and Yongyun Cho. " Cardiovascular disease analysis and risk assessment using correlation based intelligent system." In BASIC \& CLINICAL PHARMACOLOGY \& TOXICOLOGY, vol. 125, pp. 59-59. 111 RIVER ST, HOBOKEN 07030-5774, NJ USA: WILEY, 2019.

\section{AUTHORS PROFILE}

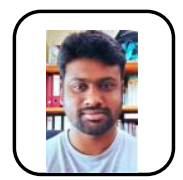

Saravana Kumar Venkatesan, is currently pursuing $\mathrm{PhD}$ in the Department of Information and Communication Engineering, Sunchon National University. He received his Bachelor degree in Mathematics from Madras university and Master of Information and Communication Engineering at sunchon National University in South Korea. His current research interests include Big Data Analytics, Data Mining, Mathematics.

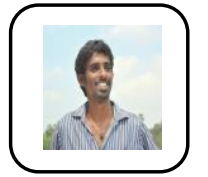

Sathish Kumar $\mathbf{V}, \mathbf{E}$, is pursuing $\mathrm{PhD}$ in the Department of Information and Communication Engineering, Sunchon National University. He received his Bachelor of Technology in Information Technology from Madras Institute of Technology and Master of Engineering in Biometrics and Cyber Security from PSG College of Technology.

His current research interests include Big Data Analytics, Data Mining, Cryptography and Vertical Farming.

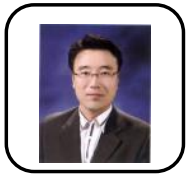

Changsun Shin, received the $\mathrm{PhD}$ degree in Computer Engineering at Wonk Wang University. Currently, he is a Professor in the Dept. of Information \& Communication Engineering, Sunchon National University. His research interests include Distributed Computing, Machine Learning, IoT and Agriculture/ICT Convergence.

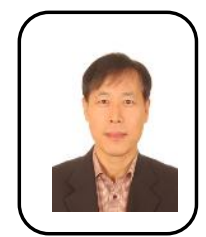

Yubin Kim, received his Bachelor and MS degree, and currently is pursuing $\mathrm{PhD}$ in the Department of Computer Science, Sunchon National University. Currently, he is a managing director of ELSYS Co, Ltd. His current research interests include Big Solar Energy System, Geothermal Energy System, IoT and Agriculture/ICT Convergence.

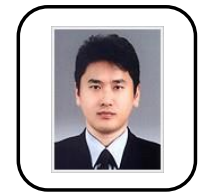

Yongyun Cho, received the $\mathrm{PhD}$ degree in Computer Engineering from Soongsil University. Currently, he is an assistant professor in the Department of Information and Communication Engineering, Sunchon National University. His research interests include System Computing. Software, Embedded Software and Ubiquitous 